\title{
A Mie Scattering Investigation of The Effect of Strain Rate on Soot Formation in Precessing Jet Flames
}

\author{
V. Stamatov $・$ L. Stamatova
}

Published online: 12 December 2007

(C) Springer Science + Business Media B.V. 2007

The referencing of the paper "A Mie scattering investigation of the effect of strain rate on soot formation in precessing flames" (FTaC 76(3): 279-289 (2006)) is changed to include:

"L. I. Stamatova, K. D. King, Z. T. Alwahabi, and G. J. Nathan, A Mie Scattering Investigation of the Zones of Soot Formation in Precessing Jet Flames, Third Australian Conference on Laser Diagnostics in Fluid Mechanics and Combustion, Proceedings, T.McIntyre, Ed., The University of Queensland, ISBN: 1-86-499659-5, 35-41 (2002)" and "L. I. Stamatova, A Mie Scattering Investigation of the Zones of Soot Formation in Precessing Jet Flames, M.Sc. Thesis, The University of Adelaide, 2003".

The paper is attributed to the University of Adelaide. The authorship of the paper is changed to become consistent with the earlier conference paper. The authors are in the same order with addition of V. Stamatov as the fifth author. In addition to the published acknowledgement, authors acknowledge the support in part by the Australian Research Council and the assistance of Dr. J. Reppell.

The online version of the original article can be found at http://dx.doi.org/10.1007/s004944-006-9016-8.

V. Stamatov $(\bowtie) \cdot$ L. Stamatova

Department of Mechanical Engineering, Monash University, Clayton, VIC 3800, Australia

e-mail: venelin.stamatov@eng.monash.edu.au 